\title{
Mechanical Properties of Tunnel Muck with Fly-Ash Geopolymer
}

\author{
Dong Yang $\mathbb{D}^{1}{ }^{1}$ Zhiqin Xi, ${ }^{1}$ Qiang Chen, ${ }^{2}$ and Shuisheng Li ${ }^{1}$ \\ ${ }^{1}$ China Construction Fifth Engineering Division Co., Ltd., Changsha, Hunan 410004, China \\ ${ }^{2}$ East China University of Technology, Nanchang, Jiangxi 330013, China \\ Correspondence should be addressed to Dong Yang; ydcscec@hotmail.com
}

Received 26 July 2019; Revised 29 October 2019; Accepted 9 December 2019; Published 12 February 2020

Guest Editor: Mbakisya A. Onyango

Copyright $\odot 2020$ Dong Yang et al. This is an open access article distributed under the Creative Commons Attribution License, which permits unrestricted use, distribution, and reproduction in any medium, provided the original work is properly cited.

The tunnel muck has a great potential to be used as a recyclable engineering material in transit and other civil work projects instead of being deposited as construction waste. In this work, the geopolymer is generated by alkali-activated fly ashes, which act as cementitious materials to strengthen the tunnel muck. The tunnel muck has to be dehydrated, grinded, and screened before being treated by alkali-activated fly ash. The effect of the mass ratio between fly ash and tunnel muck $\left(M_{\mathrm{fa}} / M_{\mathrm{tm}}\right)$, the mass ratio between $\mathrm{Na}_{2} \mathrm{SiO}_{3}$ solution and $\mathrm{NaOH}$ solution $\left(M_{\mathrm{Na}_{2} \mathrm{SiO}_{3}} / M_{\mathrm{NaOH}}\right)$, the ratio between liquid and solid $\left(M_{\text {liquid }} / M_{\text {solid }}\right)$, and molarity of $\mathrm{NaOH}$ on the strength of geopolymer were systematically studied by conducting the uniaxial compression experiments. The experimental results indicate that the liquid-to-solid ratio is the most important parameter to the geopolymer strength after the alkali-activated fly ash treatment. On the contrary, molarity of $\mathrm{NaOH}$ is less effective on the geopolymer strength. Moreover, the optimum scheme is concluded according to the experimental results as follows: the mass ratio between tunnel muck and fly ash, the mass ratio between $\mathrm{Na}_{2} \mathrm{SiO}_{3}$ solution and $\mathrm{NaOH}$ solution, the ratio between liquid and solid, and molarity of $\mathrm{NaOH}$ are $1: 2$, $1.8,0.18$, and $10 \mathrm{~mol} / \mathrm{L}$, respectively. Meanwhile, the SEM images indicate that flocculence from the active substance in fly ash is a crucial component as the cementing material.

\section{Introduction}

Tunneling structures have been well applied in urban subway construction and traffic tunnel as one of the most effective ways to enhance the urban land utilization efficiency $[1,2]$. People are even proposing to apply the tunneling structures into the Lunar exploration [3-5]. Meanwhile, a big amount of excavated materials/tunnel muck has been removed from tunnel, which has been considered to be waste material of little or no value for a long time $[6,7]$. The main contents of the tunnel muck are gravel, sand, and clay with different amount of water. The instability of these geomaterials might trigger dreadful disasters [4, 8-12]. Hence, an efficient way to deposit or even to recycle the tunnel muck is of great significance to the environment.

The gravel and sand are typical geogranular materials [13-16], whose mechanical properties have been systemically reported by using the photoelastic experimental method since the 1990s [17-21], and they can be very easily used as building materials after being filtered out from the tunnel muck. However, the clay content in the tunnel muck is always one of the trickiest parts to deal with, which is usually mixed with ameliorants like bentonite, frothier, resin, tackifier, and so forth. Efforts have been made to recycle the clay content into geopolymer as a green material all the time [22-24]. Davidovits [25] presented a new type of material called geopolymers as a possible solution to this problem, since their physical properties make them a viable alternative for many conventional cements and plastics. Compared to conventional cements, geopolymers are powerful with high chemical resistance, fire resistance, temperature resistance, and so forth [26]. In view of these superior properties, generating geopolymers by using alkali-activated fly ash to improve the bearing capacity of foundation soil has been reported recently [27, 28]. Moreover, geopolymers combined with loess and fully weathered granite were developed as useful building materials [29-31]. However, little literatures can be found on the alkali-activated fly ash as cementing material for tunnel muck. 
In this work, the geopolymer that is generated by alkaliactivated fly ash for reusing the high clay content tunnel muck is studied. For making the geopolymer samples, the advantages and disadvantages between casting method and pressing mold method are discussed. In order to understand the strength of the geopolymer sample, the orthogonal analysis is conducted based on the compression experiments by varying four different parameters. The optimum scheme to make the geopolymer sample from the high clay content is proposed eventually, which could be a valuable reference for the tunnel muck reutilization.

\section{Experimental Materials and Protocol}

2.1. Experimental Materials. The tunnel muck excavated from subway tunnel in Changsha is used to make the geopolymer. The main content of the tunnel muck here is completely weathered conglomerate with approximately $26.9 \%$ moisture content, $26.9 \%$ silt content, and $18.4 \%$ clay content. The particle size distribution of the tunnel muck is shown in Figure 1. The measured plastic limit and liquid limit of the excavated tunnel muck are $13.3 \%$ and $29.0 \%$, respectively.

Before fabricating the geopolymer, the excavated tunnel muck is dried and smashed. The fine grain muck with less than $2 \mathrm{~mm}$ diameter is picked by sieve. The X-ray fluorescence (XRF) results of a typical fine grain muck after filtering by $2 \mathrm{~mm}$ diameter sieve are shown in Table 1 . Most of the elements are $\mathrm{SiO}_{2}$ and $\mathrm{Al}_{2} \mathrm{O}_{3}$ of the fine grain muck. There is approximately 1 percent of $\mathrm{MgO}$ and very few $\mathrm{CaO}$ in the fine grain muck. The fly ash with $450 \mathrm{~m}^{2} / \mathrm{kg}$ specific surface area is applied into the tunnel muck in this work. The alkaliactivator is a mixture of $\mathrm{NaOH}$ solution and $\mathrm{Na}_{2} \mathrm{O} \cdot n \mathrm{SiO}_{2}$ in this work, where the $\mathrm{NaOH}$ solution is made by dissolving the industrial grade tablet alkali into water. The freshly prepared $\mathrm{NaOH}$ solution has to be cooled down to the room temperature before being used to make the geopolymer. In order to ensure equilibrium state in the mixture, the mixed solutions need to be stored for a minimum of 24 hours prior to use as suggested by Duxson et al. [29, 32, 33].

2.2. Experimental Protocol to Mode the Geopolymer Sample. Four different methods were tried to make the raw materials mixtures. The one that can have the highest strength sample is applied in this work. The details of the applied method include the following: (1) add a certain amount of muck in the container; (2) according to the scheme, the fly ash is well mixed with muck; and (3) the solution is poured into the muck and fly ash mixture, and well mix them. The details of the other three methods will not be introduced here, since these methods are not applied in the present work. Two prevailing procedures can be applied to make the geopolymers: casting and mold pressing (semidry pressing) [34]. By using casting method, the raw material mixtures with alkali-activated fly ash are made as flexible slurry is poured into sample mold. The geopolymers will form after a certain time. The casting method is a relatively easy method, which can even make complicated geometry geopolymer samples. Different amount of water is added into the sample to get the optimal amount of water that can make the raw material flexible. In order to pour the raw materials into the mold, a mass percentage of approximately $20 \% \sim 40 \%$ of water has to be added, which is too much. Moreover, there will always be cracks forming on the surface of geopolymer sample due to the high clay content as shown in Figure 2(a), $[35,36]$. For the mold pressing method, the raw materials mixtures with alkali-activated fly ash are made as colloidal solution to be compressed to solid sample in the mold, which requires much less water than casting method. The force applied here is $19.625 \mathrm{kN}$ with a $10 \mathrm{MPa}$ corresponding pressure. Moreover, the same pressure $(10 \mathrm{MPa})$ is used to make the samples with pressing method in this work. The geopolymer sample made by mold pressing method has relatively smooth surface as shown in Figure 2(b). Hence, the mold pressing method is applied in this work to make the geopolymers.

2.3. Uniaxial Compression Protocol. Comprehensive experiments are conducted to systemically study the effect of each parameter on the strength of geopolymers. Orthogonal experimental design is applied to schematize the uniaxial compression protocol. Four different parameters are considered as orthogonal factors, and three factor levels are involved in total. The details of the experimental protocol are shown in Table 2. The parameters include the mass ratio between fly ash and tunnel muck $\left(M_{\mathrm{fa}} / M_{\mathrm{tm}}\right)$, the mass ratio between $\mathrm{Na}_{2} \mathrm{SiO}_{3}$ solution and $\mathrm{NaOH}$ solution $\left(M_{\mathrm{Na}_{2} \mathrm{SiO}_{3}} / M_{\mathrm{NaOH}}\right)$, the mass ratio between liquid and solid $\left(M_{\text {liquid }} / M_{\text {solid }}\right)$, and molarity of $\mathrm{NaOH}$, where the mass ratio between fly ash and tunnel muck means the mass of fly ash versus the mass of dry tunnel muck here.

The geopolymer sample is pressed in a cylinder mold with a diameter of $50 \mathrm{~mm}$ and a height of $100 \mathrm{~mm}$ under $10 \mathrm{MPa}$ compression pressure. The samples are cured for 28 days before being placed on the uniaxial compression apparatus (Instron 1346). The experiments are conducted by combining stress control method and displacement control method. At the initial state, the stress control method is applied with $10 \mathrm{kN} / \mathrm{min}$ loading speed, and the $0.2 \mathrm{~mm} / \mathrm{min}$ displacement control method is applied at $80 \%$ of the estimated peak strength until complete failure stage.

\section{Experimental Results}

3.1. Stress-Strain Curve of the Geopolymers. The stress-strain curves of all $9 \times 3$ uniaxial compression experimental results are shown in Figure 3. In general, four stages can be observed in the stress-strain curves; the region of each stage on a typical stress-train curve is shown in the inset of Figure 3. The four stages include the following. (1) The first is strain hardening stage, which happens right after the initial compression. The slope of the curve tends to increase as the compression strain increases, which indicates the vertical stiffness is increasing in this stage. (2) The second is linear elastic deformation stage, at which the stress increases linearly as the strain increases. The deformation of the 


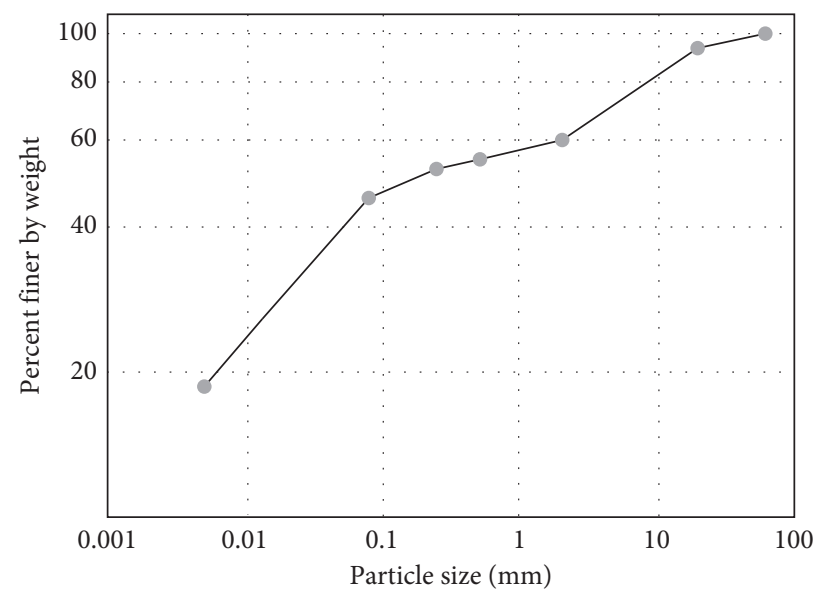

FIGURE 1: Particle size distribution of the tunnel muck.

TABLE 1: XRF results of a typical fine muck sample with the particles size less than $2 \mathrm{~mm}$.

\begin{tabular}{lccccccc}
\hline Element & $\mathrm{SiO}_{2}$ & $\mathrm{Al}_{2} \mathrm{O}_{3}$ & $\mathrm{Fe}_{2} \mathrm{O}_{3}$ & $\mathrm{~K}_{2} \mathrm{O}$ & $\mathrm{MgO}$ & $\mathrm{Ti}_{2} \mathrm{O}$ & $\mathrm{CaO}$ \\
\hline Percentage by weight (wt\%) & 72.7 & 18.10 & 3.29 & 3.51 & 1.08 & 1.03 & 0.13 \\
\hline
\end{tabular}

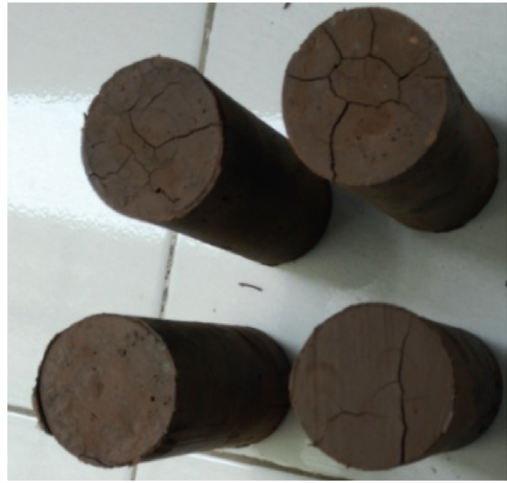

(a)

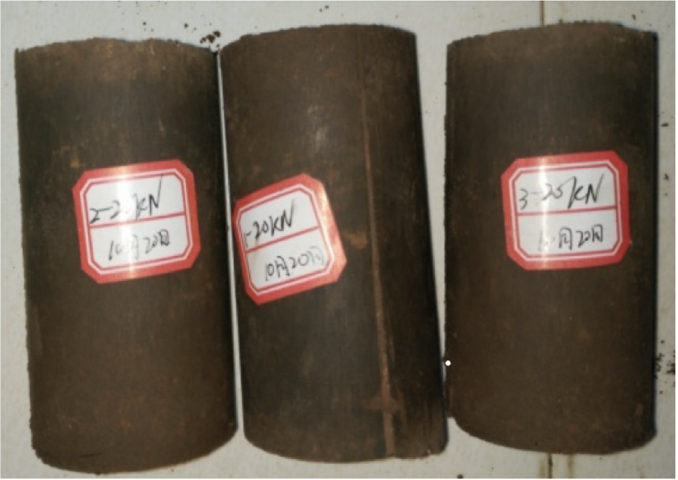

(b)

Figure 2: The typical geopolymer sample made by two methods. The same percentage of material in proportions is used for these two methods, except that $18 \%$ more water is added for casting method in order to make the raw materials able to be poured into the mold: (a) made by casting method; (b) made by pressing mold method.

TABLe 2: The details of uniaxial protocol for orthogonal experimental design.

\begin{tabular}{lcccc}
\hline No. & $M_{\mathrm{fa}} / M_{\mathrm{tm}}$ & $M_{\mathrm{Na}_{2} \mathrm{SiO}_{3}} / M_{\mathrm{NaOH}}$ & $M_{\text {liquid }} / M_{\text {solid }}$ & $\mathrm{NaOH}(\mathrm{mol} / \mathrm{L})$ \\
\hline 1 & $1: 3$ & 1.8 & 0.14 & 8 \\
2 & $1: 3$ & 2.0 & 0.16 & 10 \\
3 & $1: 3$ & 2.2 & 0.18 & 12 \\
4 & $1: 2$ & 1.8 & 0.16 & 12 \\
5 & $1: 2$ & 2.0 & 0.18 & 8 \\
6 & $1: 2$ & 2.2 & 0.14 & 10 \\
7 & $2: 3$ & 1.8 & 0.18 & 10 \\
8 & $2: 3$ & 2.0 & 0.14 & 12 \\
9 & $2: 3$ & 2.2 & 0.16 & 8 \\
\hline
\end{tabular}

geopolymer sample is recoverable after unloading in this stage. No or only a few local rearrangements happen in the sample. The maximum stress in the linear elastic deformation stage is approximately $50 \%$ of the peak stress. (3) The third is strain softening stage, where the slope of the stressstrain curve decreases as the strain increases. Cracks start to form in the sample and eventually percolate through the sample. Meanwhile, the stress is corresponding to the peak stress. (4) The fourth is post-peak-deformation stage, where the stress decreases as the strain increases. Several vertical cracks along the compression direction would be generated with the increase of strain.

3.2. Mechanical Properties of the Geopolymer Samples. Several mechanical parameters of the geopolymer samples can be extracted from the stress-strain curves, including strength, elasticity modulus, residual strength, peak strain, and tenacity. The elasticity modulus is calculated by fitting the stress-strain curves in the range from $25 \%$ to $50 \%$ of the compression strength. For the definition of residual strength, the strain at peak stress, $\gamma_{\mathrm{p}}$, is obtained from the 


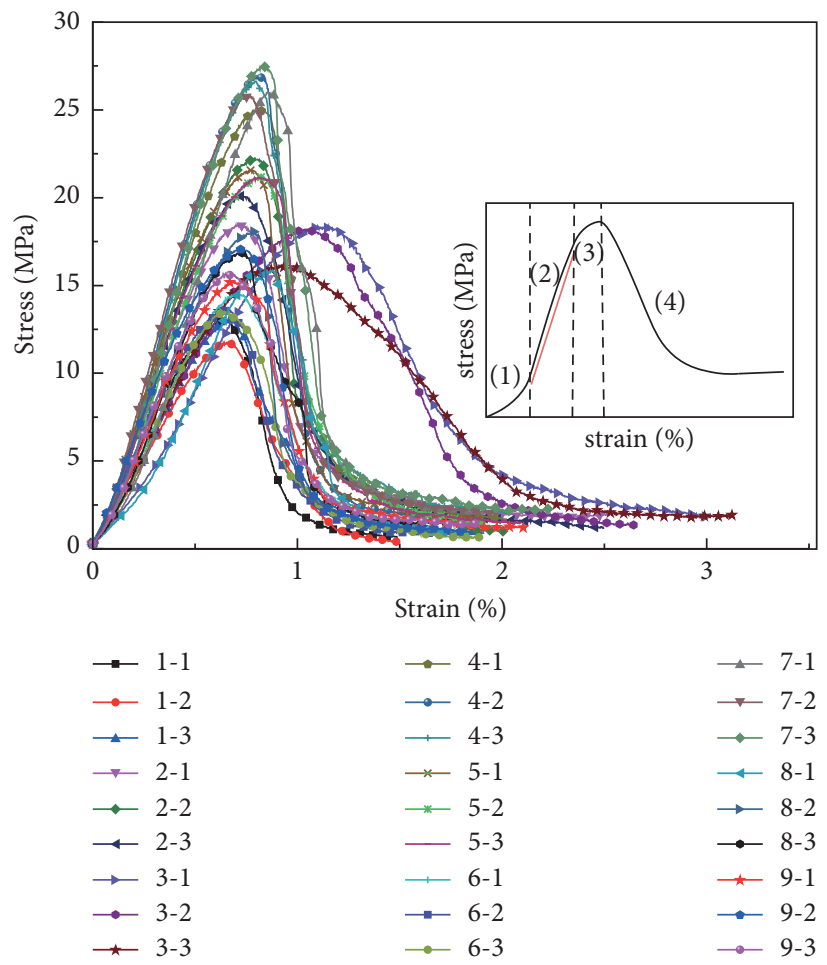

FiguRE 3: The stress-strain curves of the uniaxial experimental results. Inset: a schematic to show the four stages of a typical stress-strain curve. The red line is a reference line to indicate a linear relationship of stage 2 .

TABLE 3: Mechanical properties of the geopolymer samples from uniaxial compression experimental results.

\begin{tabular}{|c|c|c|c|c|c|c|c|c|c|}
\hline No. & $\begin{array}{l}M_{\mathrm{fa}} / \\
M_{\mathrm{tm}}\end{array}$ & $M_{\mathrm{Na}_{2} \mathrm{SiO}_{3}} / M_{\mathrm{NaOH}}$ & $\begin{array}{c}M_{\text {liquid }} / \\
M_{\text {solid }}\end{array}$ & $\begin{array}{l}\mathrm{NaOH} \\
(\mathrm{mol} / \mathrm{L})\end{array}$ & $\begin{array}{l}\text { Strength } \\
(\mathrm{MPa})\end{array}$ & $\begin{array}{l}\text { Elasticity modulus } \\
(\mathrm{GPa})\end{array}$ & $\begin{array}{l}\text { Residual strength } \\
(\mathrm{MPa})\end{array}$ & $\begin{array}{l}\text { Peak strain } \\
\left(\times 10^{-3}\right)\end{array}$ & $\begin{array}{l}\text { Tenacity } \\
\left(\mathrm{J} / \mathrm{m}^{3}\right)\end{array}$ \\
\hline 1 & $1: 3$ & 1.8 & 0.14 & 8 & 12.61 & 2.44 & 1.22 & 6.31 & 83.02 \\
\hline 2 & $1: 3$ & 2.0 & 0.16 & 10 & 20.27 & 3.50 & 2.81 & 7.08 & 163.22 \\
\hline 3 & $1: 3$ & 2.2 & 0.18 & 12 & 17.54 & 2.28 & 3.88 & 9.82 & 229.41 \\
\hline 4 & $1: 2$ & 1.8 & 0.16 & 12 & 26.18 & 4.40 & 2.52 & 7.41 & 186.26 \\
\hline 5 & $1: 2$ & 2.0 & 0.18 & 8 & 21.29 & 3.80 & 2.08 & 7.55 & 161.52 \\
\hline 6 & $1: 2$ & 2.2 & 0.14 & 10 & 13.87 & 2.60 & 1.56 & 6.35 & 96.73 \\
\hline 7 & $2: 3$ & 1.8 & 0.18 & 10 & 26.41 & 4.31 & 2.82 & 7.27 & 190.91 \\
\hline 8 & $2: 3$ & 2.0 & 0.14 & 12 & 16.93 & 2.79 & 1.31 & 7.30 & 112.47 \\
\hline 9 & $2: 3$ & 2.2 & 0.16 & 8 & 15.98 & 3.11 & 1.91 & 6.56 & 118.35 \\
\hline
\end{tabular}

stress-strain curve first, and then the stress at the strain equaling $2 \gamma_{\mathrm{p}}$ is defined as residual strength. The stress usually reaches a stable state after the strain becomes twice bigger than that at the peak stress. Hence, the stress at the strain twice bigger than that at the peak stress is defined as the residual strength. The tenacity is defined as the area under the stress-strain curve. The mechanical properties of the geopolymer samples from uniaxial compression experimental results are shown in Table 3, where all the mechanical parameters are averaged over three experiments with the same initial condition.

\section{Discussions}

As shown in Table 3, group 7 sample has the maximum strength, which is $26.41 \mathrm{MPa}$. Group 4 has the highest elasticity modulus of $4.40 \mathrm{GPa}$. The maximum residual strength is $3.88 \mathrm{MPa}$, which is exhibited by group 3. The peak strain of the tested geopolymer samples is located in $6.31 \times 10^{-3} \sim 9.82 \times 10^{-3}$, which is several times bigger than the peak strain of concrete [37]. The average residual strength is approximately $11.9 \%$ of the peak strength.

The orthogonal analysis is applied to understand the importance of each parameter to the strength and tenacity of the geopolymer sample $[38,39]$. The details of orthogonal analysis are shown in Table 4 . The results indicate that the liquid/solid ratio is the most important parameter to the geopolymer strength after the alkali-activated fly ash treatment. On the contrary, the geopolymer strength is less sensitive to molarity of $\mathrm{NaOH}$. Meanwhile, the optimum scheme is concluded according to the experimental results as follows: the mass ration between fly ash and tunnel muck, 
TABLe 4: Details of orthogonal analysis.

\begin{tabular}{|c|c|c|c|c|c|}
\hline & Index & $M_{\mathrm{fa}} / M_{\mathrm{tm}}$ & $M_{\mathrm{Na}_{2} \mathrm{SiO}_{3}} / M_{\mathrm{NaOH}}$ & $M_{\text {liquid }} / M_{\text {solid }}$ & $\mathrm{NaOH}(\mathrm{mol} / \mathrm{L})$ \\
\hline \multirow{8}{*}{ Strength $(\mathrm{MPa})$} & K1 & 50.42 & 65.20 & 43.41 & 49.88 \\
\hline & $\mathrm{K} 2$ & 61.34 & 58.49 & 62.43 & 60.55 \\
\hline & K3 & 59.32 & 47.39 & 65.24 & 60.65 \\
\hline & $\mathrm{k} 1$ & 16.81 & 21.73 & 14.47 & 16.63 \\
\hline & $\mathrm{k} 2$ & 20.45 & 19.50 & 20.81 & 20.18 \\
\hline & $\mathrm{k} 3$ & 19.77 & 15.80 & 21.75 & 20.22 \\
\hline & $\mathrm{R}$ & 3.64 & 5.93 & 7.28 & 3.59 \\
\hline & $\begin{array}{l}\text { Weight of influence factors } \\
\text { Optimal solution }\end{array}$ & \multicolumn{4}{|c|}{$\begin{array}{c}M_{\text {liquid }} / M_{\text {solid }}>M_{\mathrm{Na}_{2} \mathrm{SiO}_{3}} / M_{\mathrm{NaOH}}>M_{\mathrm{fa}} / M_{\mathrm{tm}}>\mathrm{NaOH} \\
2132\end{array}$} \\
\hline \multirow{8}{*}{ Tenacity $\left(\mathrm{J} / \mathrm{m}^{3}\right)$} & $\mathrm{K} 1$ & 475.65 & 460.19 & 292.22 & 362.89 \\
\hline & $\mathrm{K} 2$ & 444.51 & 437.21 & 467.83 & 450.86 \\
\hline & K3 & 421.73 & 444.49 & 581.84 & 528.14 \\
\hline & k1 & 158.55 & 153.40 & 97.41 & 120.96 \\
\hline & $\mathrm{k} 2$ & 148.17 & 145.74 & 155.94 & 150.29 \\
\hline & $\mathrm{k} 3$ & 140.58 & 148.16 & 193.95 & 176.05 \\
\hline & $\mathrm{R}$ & 17.97 & 7.66 & 96.54 & 55.08 \\
\hline & $\begin{array}{l}\text { Weight of influence factors } \\
\text { Optimal solution }\end{array}$ & \multicolumn{4}{|c|}{$\begin{array}{c}M_{\text {liquid }} / M_{\text {solid }}>\mathrm{NaOH}>M_{\mathrm{fa}} / M_{\mathrm{tm}}>M_{\mathrm{Na}_{2} \mathrm{SiO}_{3}} / M_{\mathrm{NaOH}} \\
1133\end{array}$} \\
\hline
\end{tabular}
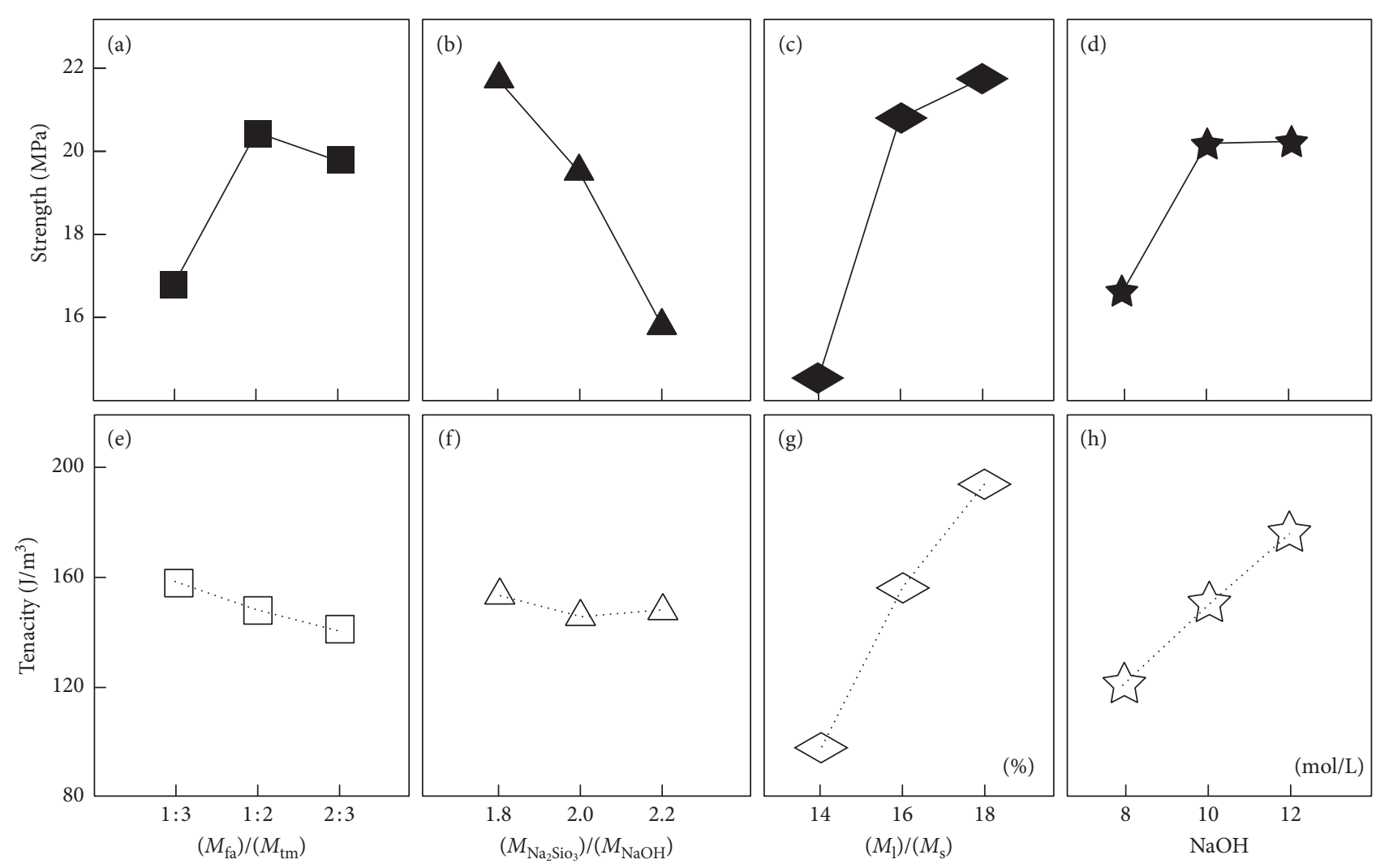

Figure 4: The strength and tenacity affected by each parameter.

the mass ratio between $\mathrm{Na}_{2} \mathrm{SiO}_{3}$ solution and $\mathrm{NaOH}$ solution, the ratio between liquid and solid, and molarity of $\mathrm{NaOH}$ are $1: 2,1.8,0.18$, and $10 \mathrm{~mol} / \mathrm{L}$, respectively.

The effects of the mass ratio between fly ash and tunnel muck $\left(M_{\mathrm{fa}} / M_{\mathrm{tm}}\right)$, the mass ratio between $\mathrm{Na}_{2} \mathrm{SiO}_{3}$ solution and $\mathrm{NaOH}$ solution $\left(M_{\mathrm{Na}_{2} \mathrm{SiO}_{3}} / M_{\mathrm{NaOH}}\right)$, the ratio between liquid and solid $\left(M_{\text {liquid }} / M_{\text {solid }}\right)$, and molarity of $\mathrm{NaOH}$ on the strength of geopolymer are shown in Figures 4(a)-4(d). The strength approaches the highest value when $M_{\mathrm{fa}}$ : $M_{\mathrm{tm}}=1: 2$ and molarity of $\mathrm{NaOH}$ is $10 \mathrm{~mol} / \mathrm{L}$. The strength increases as the $M_{\text {liquid }} / M_{\text {solid }}$ increases, which is one of the most important control factors to the geopolymer strength. However, it is hard to make the geopolymer sample with $M_{\text {liquid }} / M_{\text {solid }}>0.2$ as the mixture would be squeezing out 


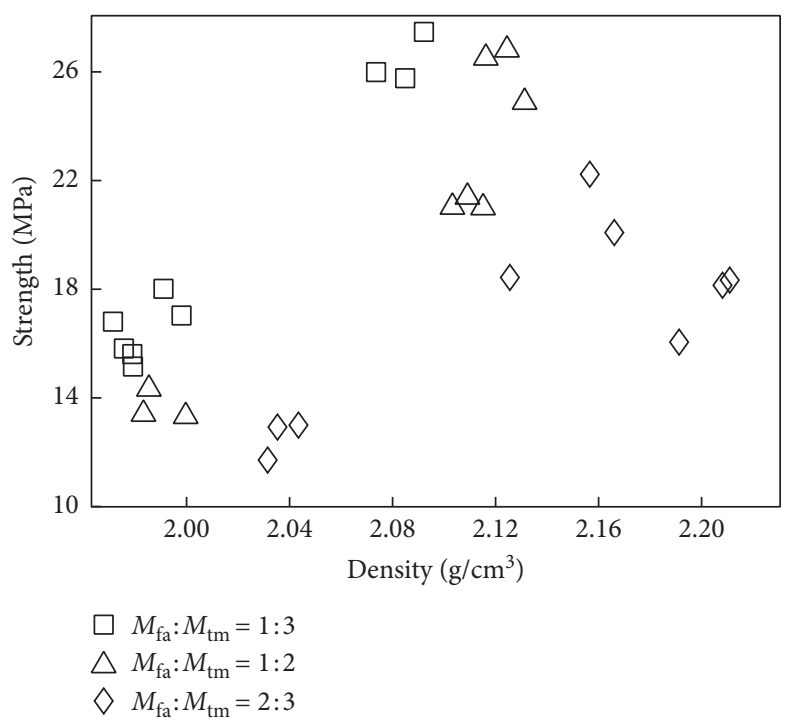

FIGURE 5: The density of geopolymer sample versus strength for different $M_{\mathrm{fa}}: M_{\mathrm{tm}}$.
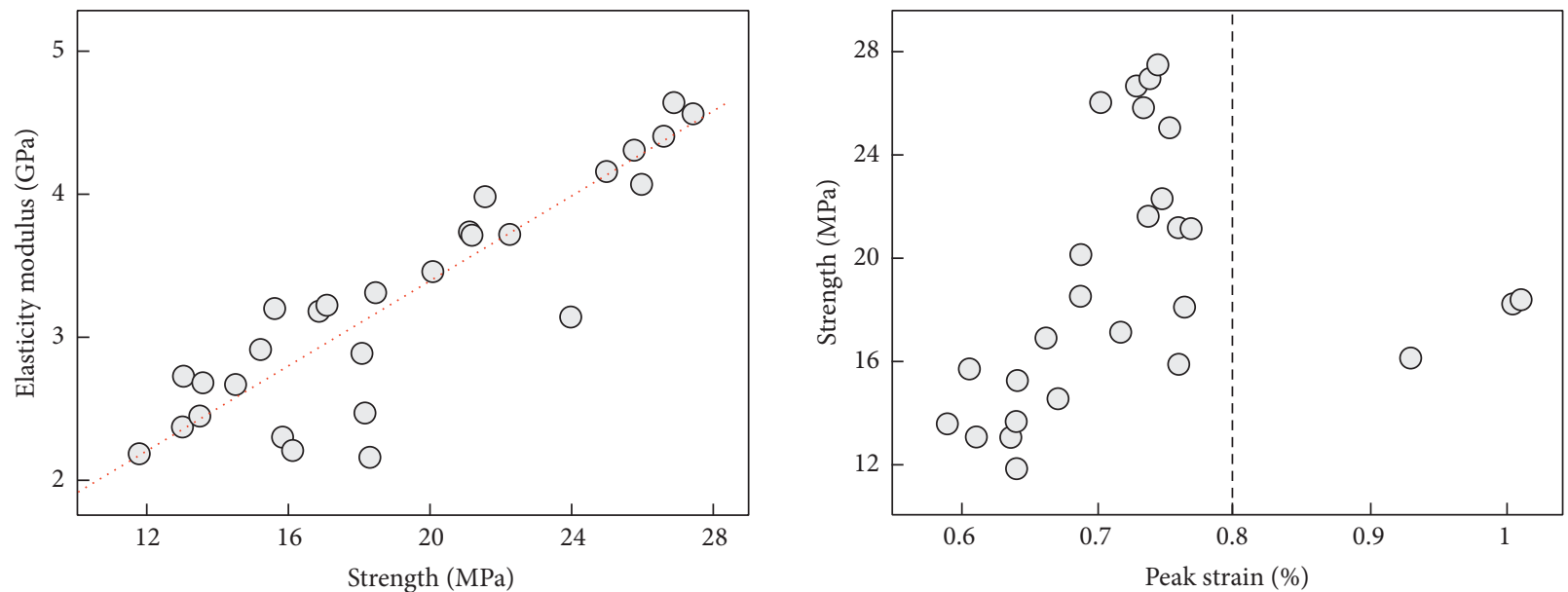

$\bigcirc$ Experimental data

Fitting curve

(a)

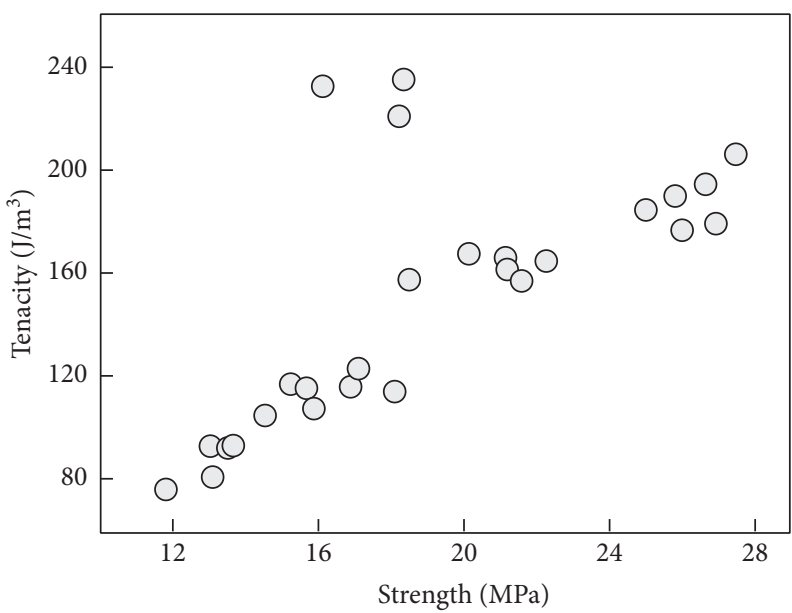

(c) (b)

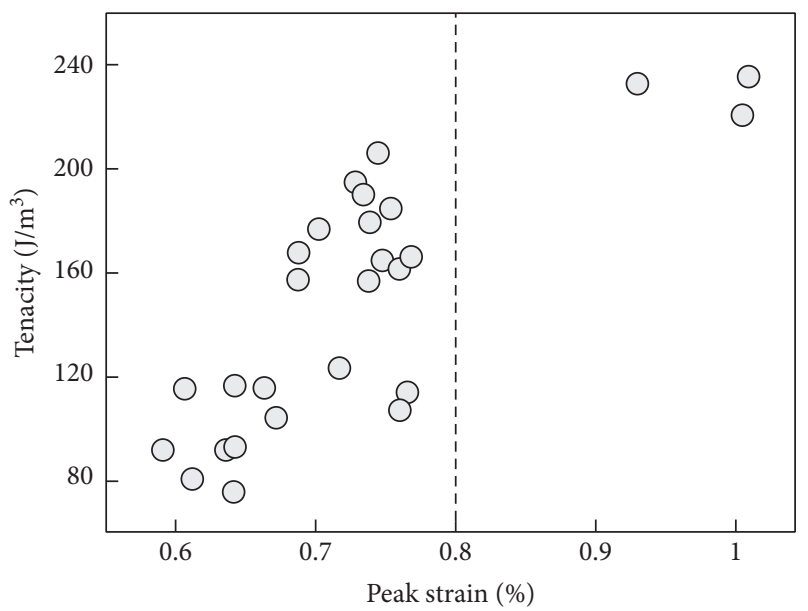

(d)

FIgURE 6: The strength and corresponding peak strain as a function of tenacity, elasticity modulus, and so forth. 

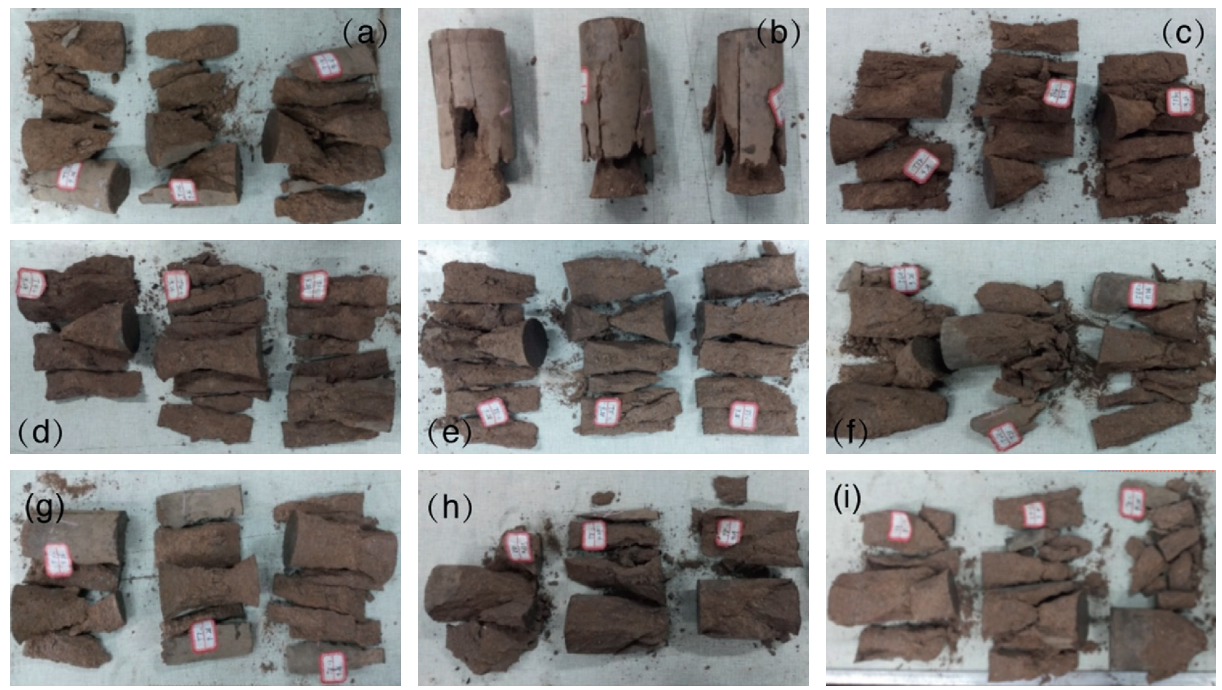

FiguRE 7: Pictures of geopolymer samples after uniaxial compression tests. Each row has the same $M_{\mathrm{fa}} / M_{\mathrm{tm}}$ values, which are $1: 3,1: 2$, and $2: 3$ from the first to the third row, respectively. Each column has the same $M_{\mathrm{Na}_{2} \mathrm{SiO}_{3}} / M_{\mathrm{NaOH}}$ values, which are 1:8, 2.0, and 2.2 from the first column to the third column, respectively. $M_{\text {liquid }} / M_{\text {solid }}$ ratios of each raw vary among $0.14,0.16$, and 0.18 . The $\mathrm{NaOH}$ concentrations of each row vary among 8,10 , and 12 . The details of the $M_{\text {liquid }} / M_{\text {solid }}$ ratios and $\mathrm{NaOH}$ concentration can refer to Table 2.
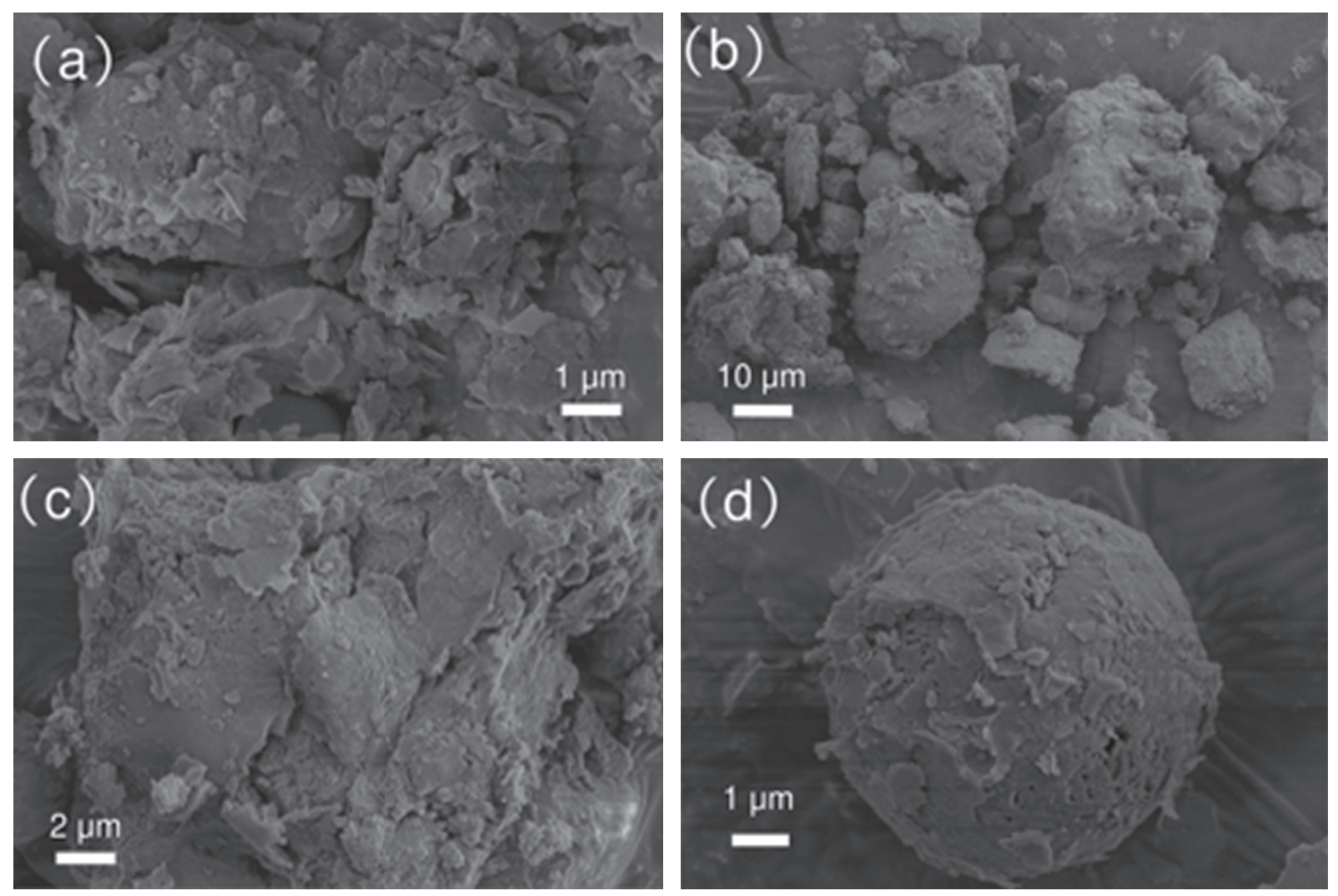

FIGURE 8: Different scale of SEM images of geopolymer sample: (a) the soil particle and fly ashes are strengthened by flocculence; (b) 10-time zoomed out view of (a); (c) the materials that were not involved in the chemical reaction, which are filler and skeleton of geopolymer sample; (d) typical fly ash particle after the reaction with structural holes on the surface.

from the mold. The ratio $M_{\text {liquid }} / M_{\text {solid }}=0.18$ is set to make the geopolymer in this work. $M_{\mathrm{Na}_{2} \mathrm{SiO}_{3}} / M_{\mathrm{NaOH}}$ is another important factor to the geopolymer strength, which has a negative correlation with the geopolymer strength. The tenacity of the geopolymer sample affected by these four influence factors is shown in Figures 4(e)-4(h). According to 
the orthogonal analysis results in Table 4, the geopolymer sample has the highest tenacity at $M_{\mathrm{fa}}: M_{\mathrm{tm}}=1: 3$, $M_{\mathrm{Na}_{2} \mathrm{SiO}_{3}} / M_{\mathrm{NaOH}}=1.8, M_{\text {liquid }} / M_{\text {solid }}=0.8$, and molarity of $\mathrm{NaOH}$ is $12 \mathrm{~mol} / \mathrm{L}$.

Microscale pore filled by the agglutination aggregates is another important factor that can influence the strength of geopolymer sample. The filling degree can be estimated by the density of geopolymer sample, which has positive correlation with the density. Figure 5 shows the strength of the geopolymer sample as a function of density for different mass ratio between fly ash and tunnel muck. The strength increases as the density increases when $M_{\mathrm{fa}}: M_{\mathrm{tm}}=1: 2$ and $2: 3$. However, when $M_{\mathrm{fa}}: M_{\mathrm{tm}}=1: 3$, the strength increases to approximately $20 \mathrm{MPa}$ as the density increases and then decreases.

The scatter of strength and tenacity versus elasticity modulus and peak strain is shown in Figure 6. The peak strain seems to have an asymptotic value of $8 \times 10^{-3}$, which is indicated by the dashed lines in Figures 6(c) and 6(d). Both of elastic modulus and tenacity show positive correlation with strength, while the strength $\left(\sigma_{0}\right)$ and elasticity modulus (E) can be fitted by a linear equation as

$$
E=0.148 \sigma_{0}+0.428
$$

The pictures of failure geopolymer sample are shown in Figure 7. A cone geometry part can be found for almost every failure sample, which might be due to the basal friction between the machine and sample. Meanwhile, an " $\mathrm{X}$ " shape shear band geometry can also be found in the failure sample as shown in Figure $7(\mathrm{~g})[16,40]$. There is another uncommon failure as shown in Figure 7 , where the top of the sample is relatively complete, while the bottom of the sample is broken into pieces. This might be caused by the inhomogeneous density distribution in the sample, which results from the high friction between the sample and the mode stopping the sample from sliding down under compression applied from the top [41]. A much dense top and less dense bottom would form in this case.

Different microscopic levels of scanning electron microscope (SEM) tests were conducted to understand the microscope structure of the geopolymer. The SEM images are shown in Figure 8, the flocculence is geopolymers, spheres are fly ashes, and bulks are soil particles. The fly ashes and soil particles are wrapped by flocculence (Figures $8(\mathrm{a})$ and $8(\mathrm{~b})$ ) to strengthen the sample. The flocculence is mainly from the chemical reaction of active substance in fly ashes. The left materials without chemical reaction became filler and skeleton of geopolymer sample, as shown in Figure 8(c). The corrosion on the surface of fly ash particle can be seen after the chemical reaction; several structural holes are visible as shown in Figure 8(d).

\section{Conclusions}

The mechanical properties of the geopolymer made by different recipes are reported. The strength, tenacity, and residual strength are analyzed systematically. The orthogonal analysis is applied to understand the effects of the mass ratio between fly ash and tunnel muck $\left(M_{\mathrm{fa}} / M_{\mathrm{tm}}\right)$, the mass ratio between $\mathrm{Na}_{2} \mathrm{SiO}_{3}$ solution and $\mathrm{NaOH}$ solution $\left(M_{\mathrm{Na}_{2} \mathrm{SiO}_{3}} / M_{\mathrm{NaOH}}\right)$, the ratio between liquid and solid $\left(M_{\text {liquid }} / M_{\text {solid }}\right)$, and molarity of $\mathrm{NaOH}$ on the strength of geopolymer. Our experimental study has made the following findings:

(1) The pressing mold method is better than casting method for the tunnel muck with high clay content. In order to make high-strength geopolymer sample, the dry soil and fly ash should be mixed homogeneously together first and then mixed with alkaliactivator.

(2) The orthogonal analyses conclude that the optimum scheme for making geopolymer sample is to set the mass ration between fly ash and tunnel muck, the mass ratio between $\mathrm{Na}_{2} \mathrm{SiO}_{3}$ solution and $\mathrm{NaOH}$ solution, the ratio between liquid and solid, and molarity of $\mathrm{NaOH}$ to be $1: 2,1.8,0.18$, and $10 \mathrm{~mol} / \mathrm{L}$, respectively.

(3) The failure of geopolymer sample shows cone geometry part and " $X$ " shape shear failure. The SEM images show that the flocculence from the active substance in fly ash is a crucial component as the cementing material.

\section{Data Availability}

The data used to support the findings of this study are included within the article.

\section{Conflicts of Interest}

The authors declare that there are no conflicts of interest regarding the publication of this paper.

\section{Acknowledgments}

This work was supported by the China State Construction Engineering Corporation Limited Funded Project (Grant no. CSCEC-2018-Z-1), Natural Science Foundation of Hunan Province, China (Grant no. 2018JJ3578), and China Construction Fifth Engineering Division Group., LTD, Funded Project (Grant no. CSCEC5b-2017-03).

\section{References}

[1] W. Liu, T. Zhao, W. Zhou, and J. Tang, "Safety risk factors of metro tunnel construction in China: an integrated study with EFA and SEM," Safety Science, vol. 105, pp. 98-113, 2018.

[2] P. Li, Y.-w. Zhang, F.-y. Jiang, and H. Zheng, "Comprehensive health assessment of shield tunnel structure based on prototype experiment," Journal of Central South University, vol. 25, no. 3, pp. 681-689, 2018.

[3] J. Rostami, C. Dreyer, and B. Blair, "Lunar tunnel boring machines," in Proceedings of the 16th Biennial International Conference on Engineering, Science, Construction, and Operations in Challenging Environments, pp. 240-252, American Society of Civil Engineers, Cleveland, OH, USA, April 2018. 
[4] H. Zheng and Y. Huang, "Model tests on flow slide of lunar regolith simulant," Environmental Earth Sciences, vol. 73, no. 8, pp. 4853-4859, 2015.

[5] Y. Huang and H. Zheng, "Mechanical characteristics of a lunar regolith simulant at low confining pressure," Environmental Earth Sciences, vol. 71, no. 8, pp. 3697-3703, 2014.

[6] R. Bellopede, M. Francini, P. Marini, A. Migheli, E. Moretti, and P. Oreste, "Alkali aggregate reaction for concrete made with tunnel muck: experimental investigations," in Engineering Geology for Society and Territory-Volume 5: Urban Geology, Sustainable Planning and Landscape Exploitation, pp. 81-84, Springer, Berlin, Germany, 2015.

[7] R. Bellopede, D. Colaiacomo, P. Marini, P. Oreste, and O. Radis, "The aggregates from tunnel muck and their use as secondary raw material: the case study of turin underground," in Engineering Geology for Society and Territory-Volume 5: Urban Geology, Sustainable Planning and Landscape Exploitation, pp. 75-79, Springer, Berlin, Germany, 2015.

[8] W. Zhang, H. Zheng, F. Jiang, Z. Wang, and Y. Gao, "Stability analysis of soil slope based on a water-soil-coupled and parallelized Smoothed Particle Hydrodynamics model," Computers and Geotechnics, vol. 108, pp. 212-225, 2019.

[9] Y. Huang, H. Zheng, W. Mao, G. Li, and B. Ye, "Numerical simulation of air-soil two-phase flow based on turbulence modeling," Natural Hazards, vol. 58, no. 1, pp. 311-323, 2011.

[10] Y. Huang, H. Zheng, W. Mao, M. Huang, and G. Li, “Triaxial tests on the fluidic behavior of post-liquefaction sand," Environmental Earth Sciences, vol. 67, no. 8, pp. 2325-2330, 2012.

[11] Y. Huang, H. Zheng, and Z. Zhuang, "Seismic liquefaction analysis of a reservoir dam foundation in the South-North Water Diversion Project in China. Part I: liquefaction potential assessment," Natural Hazards, vol. 60, no. 3, pp. 1299-1311, 2012.

[12] Y. Huang, H. Zheng, and Z. Zhuang, "Seismic liquefaction analysis of a reservoir dam foundation in the South-North Water Diversion Project in China. Part II: seismic response simulation," Natural Hazards, vol. 60, no. 3, pp. 1313-1324, 2012.

[13] H. M. B. Al-Hashemi and O. S. B. Al-Amoudi, "A review on the angle of repose of granular materials," Powder Technology, vol. 330, pp. 397-417, 2018.

[14] A. D. Burnett and P. G. D. Whiteside, "Dredged sand and gravel for construction purposes: an assessment procedure and Hong-Kong case-study," Journal of Coastal Research, vol. 8, no. 1, pp. 105-124, 1992.

[15] D. Penumadu and R. Zhao, "Triaxial compression behavior of sand and gravel using artificial neural networks (ANN)," Computers and Geotechnics, vol. 24, no. 3, pp. 207-230, 1999.

[16] H. Zheng, D. Wang, and R. P. Behringer, "Experimental study on granular biaxial test based on photoelastic technique," Engineering Geology, vol. 260, Article ID 105208, 2019.

[17] Y. Zhao, H. Zheng, D. Wang, M. Wang, and R. P. Behringer, "Particle scale force sensor based on intensity gradient method in granular photoelastic experiments," New Journal of Physics, vol. 21, no. 2, Article ID 023009, 2019.

[18] H. Zheng, D. Wang, D. Z. Chen, M. Wang, and R. P. Behringer, "Intruder friction effects on granular impact dynamics," Physical Review E, vol. 98, no. 3, 2018.

[19] H. Zheng, D. Wang, J. Bares, and R. P. Behringer, "Sinking in a bed of grains activated by shearing," Physical Review E, vol. 98, no. 1, Article ID 010901, 2018.

[20] D. Wang, J. Ren, J. A. Dijksman, H. Zheng, and R. P. Behringer, "Microscopic origins of shear jamming for $2 \mathrm{D}$ frictional grains," Physical Review Letters, vol. 120, no. 20, Article ID 208004, 2018.

[21] H. Zheng, J. A. Dijksman, and R. P. Behringer, "Shear jamming in granular experiments without basal friction," $E P L$ (Europhysics Letters), vol. 107, no. 3, p. 34005, 2014.

[22] L. Yun-Ming, H. Cheng-Yong, M. M. Al Bakri, and K. Hussin, "Structure and properties of clay-based geopolymer cements: a review," Progress in Materials Science, vol. 83, pp. 595-629, 2016.

[23] B. Singh, G. Ishwarya, M. Gupta, and S. K. Bhattacharyya, "Geopolymer concrete: a review of some recent developments," Construction and Building Materials, vol. 85, pp. 78-90, 2015.

[24] X. Y. Zhuang, L. Chen, S. Komarneni et al., "Fly ash-based geopolymer: clean production, properties and applications," Journal of Cleaner Production, vol. 125, pp. 253-267, 2016.

[25] J. Davidovits, "Man-made rock geosynthesis and the resulting development of very early high strength cement," Journal of Materials Education, vol. 16, no. 2, pp. 91-139, 1994.

[26] K. Komnitsas and D. Zaharaki, "Geopolymerisation: a review and prospects for the minerals industry," Minerals Engineering, vol. 20, no. 14, pp. 1261-1277, 2007.

[27] N. Cristelo, S. Glendinning, T. Miranda, D. Oliveira, and R. Silva, "Soil stabilisation using alkaline activation of fly ash for self compacting rammed earth construction," Construction and Building Materials, vol. 36, pp. 727-735, 2012.

[28] C. Suksiripattanapong, S. Horpibulsuk, P. Chanprasert, P. Sukmak, and A. Arulrajah, "Compressive strength development in fly ash geopolymer masonry units manufactured from water treatment sludge," Construction and Building Materials, vol. 82, pp. 20-30, 2015.

[29] P. Duxson, J. L. Provis, G. C. Lukey, S. W. Mallicoat, W. M. Kriven, and J. S. J. van Deventer, "Understanding the relationship between geopolymer composition, microstructure and mechanical properties," Colloids and Surfaces A: Physicochemical and Engineering Aspects, vol. 269, no. 1-3, pp. 47-58, 2005.

[30] J.-B. M. Dassekpo, X. Zha, and J. Zhan, "Compressive strength performance of geopolymer paste derived from completely decomposed granite (CDG) and partial fly ash replacement," Construction and Building Materials, vol. 138, pp. 195-203, 2017.

[31] J.-B. M. Dassekpo, X. Zha, and J. Zhan, "Synthesis reaction and compressive strength behavior of loess-fly ash based geopolymers for the development of sustainable green materials," Construction and Building Materials, vol. 141, pp. 491-500, 2017.

[32] P. Duxson, A. Fernández-Jiménez, J. L. Provis, G. C. Lukey, A. Palomo, and J. S. J. van Deventer, "Geopolymer technology: the current state of the art," Journal of Materials Science, vol. 42, no. 9, pp. 2917-2933, 2007.

[33] P. Duxson, G. C. Lukey, F. Separovic, and J. S. J. van Deventer, "Effect of alkali cations on aluminum incorporation in geopolymeric gels," Industrial \& Engineering Chemistry Research, vol. 44, no. 4, pp. 832-839, 2005.

[34] H. Y. Leong, D. E. L. Ong, J. G. Sanjayan, and A. Nazari, "Strength development of soil-fly ash geopolymer: assessment of soil, fly ash, alkali activators, and water," Journal of $M a$ terials in Civil Engineering, vol. 30, no. 8, Article ID 04018171, 2018.

[35] P. Boivin, P. Garnier, and D. Tessier, "Relationship between clay content, clay type, and shrinkage properties of soil samples," Soil Science Society of America Journal, vol. 68, no. 4, pp. 1145-1153, 2004. 
[36] J. M. Kanema, "The influence of soil content on the mechanical properties, drying shrinkage and autogenous shrinkage of earth concrete," Journal of Building Engineering, vol. 13, pp. 68-76, 2017.

[37] M. M. Attard and S. Setunge, "Stress-strain relationship of confined and unconfined concrete," ACI Materials Journal, vol. 93, no. 5, pp. 432-442, 1996.

[38] T. Mizuno, S. Kinoshita, T. Ito, S. Maedera, and H. Kusuhara, "Development of orthogonal linear separation analysis (OLSA) to decompose drug effects into basic components," Scientific Reports, vol. 9, no. 1, 2019.

[39] Z. Wu, W. Wang, D. Wang, K. Zhao, and W. Zhang, "Global sensitivity analysis using orthogonal augmented radial basis function," Reliability Engineering \& System Safety, vol. 185, pp. 291-302, 2019.

[40] H. Zheng, D. Wang, X. Tong, L. Li, and R. P. Behringer, "Granular scale responses in the shear band region," Granular Matter, vol. 21, no. 4, p. 107, 2019.

[41] D. E. M. Gooding, "Improved processes for the production of soil-cement building blocks," Ph. D. thesis, Department of Philosophy in the Faculty of Engineering, The University of Warwick, Coventry, UK, 1994. 